\title{
Stimulus control of ovulation in red-backed voles (Clethrionomys gapperi)
}

\author{
BRUCE FERGUSON, DANIEL G. WEBSTER, and DONALD A. DEWSBURY \\ University of Florida, Gainesville, Florida
}

\begin{abstract}
Reproductive function is under the control of stimuli mediated by the central nervous system in many species. In species classified as "induced ovulators," ovulation is generally contingent on external stimuli, particularly the vaginal stimulation derived from males during copulation. However, although they are classified as induced ovulators, 7 of 17 female redbacked voles (Clethrionomys gapperi) ovulated when housed either across a mesh barrier from a male or in isolated cages in a room containing males. There was no appreciable difference as a function of housing condition. Thus, red-backed voles ovulate in response to a variety of stimuli and do not require copulatory stimulation. Unmated Clethrionomys appear to ovulate more readily than do Microtus. The category of "induced ovulation" requires refinement.
\end{abstract}

The females of mammalian species vary greatly with respect to the stimulus control of pivotal events in their reproductive cycles. In many species (e.g., most primates), both ovulation and pseudopregnancy (i.e., the initiation of a functional luteal phase with the secretion of substantial levels of progesterone) are "spontaneous" in that they occur in virtually every cycle and are unaffected by sterile copulations (Conaway, 1971). In other species, however, ovulation, pseudopregnancy, or both may be "induced." Typically, vaginal stimulation, either from copulation with a male or from experimental intervention, triggers critical hormone release and ovulation within hours after stimulation. Species with induced ovulation, such as microtine rodents, are ideal for the study of stimulus modulation of reproductive processes.

It is generally recognized that induced and spontaneous ovulation represent, not a dichotomy, but ends of a continuum (Conaway, 1971). Under some conditions, for example, species that generally ovulate spontaneously (e.g., rats and humans) may function as induced ovulators (Aron, Roos, \& Asch, 1968; Clark \& Zarrow, 1971; Zarrow \& Clark, 1968). Similarly, species that are generally classified as induced ovulators sometimes ovulate in the absence of vaginal stimulation (e.g., Milligan, 1974, 1975). Such ovulation may still be stimulus dependent, being triggered via "remote control" (Clarke \& Hellwing, 1977) by other stimuli emanating from adult males. Such stimuli generally appear to be olfactory in nature. In a typical experiment, females may be tested under three conditions (e.g., Clarke \& Clulow, 1973). In one condition, females mate with an

This research was supported by Grant BNS-8200689 from the National Science Foundation. We thank Peter Dalby for providing breeding stock and Barbara McGuire for histological work. Reprints can be obtained from D. A. Dewsbury, Department of Psychology, University of Florida, Gainesville, FL 32611. intact or vasectomized male and ovulation is induced. In a second condition, females are housed in proximity to a male, often with some type of mesh barrier separating them. Thus, olfactory, auditory, visual, and limited tactile communication is possible. Females sometimes ovulate under such conditions (e.g., Clarke \& Clulow, 1973; Milligan, 1974). In the third condition, females are housed at some distance from males. Thus, ovulation can be studied in response to copulation, proximal noncopulatory stimulation, and distant stimulation.

Microtine rodents are ideal animals for the study of stimulus control of reproductive processes because they are induced ovulators that are common in much of North America and many species adapt well to the laboratory (Dewsbury, 1972). Red-backed voles (Clethrionomys gapperi) are widely distributed in the United States and Canada and are amenable to laboratory study (Dewsbury, Baumgardner, Sawrey, \& Webster, 1982). Langford and Clulow (1979) demonstrated that red-backed voles are induced ovulators. They found corpora lutea in the ovaries of 8 of 10 mated females and 0 of 10 unmated females. They noted, however, that no tests of effects of stimuli other than copulation were undertaken. In the present work, we explore the possibility that stimuli other than copulation can indeed trigger ovulation in red-backed voles.

\section{METHOD}

Red-backed voles, $C$. gapperi, were bred in the colony at the University of Florida. The colony was derived from stock trapped near Clarion, Pennsylvania, in 1979. All voles were at least 60 days of age at the beginning of the study and had continuous access to Purina rabbit chow and water. The entire experiment was conducted in the colony room in which both male and female voles (C. gapperi and Microtus ochrogaster) were housed. The room was maintained on a reversed 16-h-light:8-h-dark photoperiod.

Females were caged in one of two conditions. Seven females were caged individually in plastic cages measuring $29 \times 19 \times$ 
$13 \mathrm{~cm}$ (individual condition). Fifteen females were placed on one side of partitioned cages measuring $8 \times 27 \times 13 \mathrm{~cm}$ (paired condition). The other half of the cage was occupied by a male; the animals were separated by one layer of woven wire mesh.

Daily vaginal smears were taken with tap water and a thin wire loop. Upon showing 2 consecutive days of vaginal estrus (i.e., preponderance of cornified cells), all individually caged females and 12 females from the paired condition were killed and their ovaries and oviducts dissected out. Two females from the paired condition were mated on the 2 nd day of estrus and killed 1 day later.

Ovaries were embedded in paraffin, sectioned serially at 10 microns, stained with haematoxylin and eosin, and examined microscopically. The presence of corpora lutea was noted and recorded. The oviducts of all except two unmated, paired females were checked for ova. Two methods were used with different animals. In one, the tubes were pressed between two microscope slides and examined under a light microscope for the presence of ova. With the second method, a 32-ga blunted needle was inserted into the ovarian end of each tube and the tube was flushed with physiological saline. The fluid was collected, pressed gently between a microscope slide and a coverslip, and examined under a light microscope. Although neither method appears to be infallible, ova were detected using each.

\section{RESULTS}

Consistent with the observations of Langford and Clulow (1979), there was no regular cyclicity in the pattern of vaginal smears. All females except one in the paired condition and two in the unpaired condition reached the criterion of 2 consecutive days of estrus. From 3 to 92 days were required to reach the criterion.

Both ova and copora lutea were found in the two mated females. They had a mean of 5.0 corpora lutea (range $=3-7$ ) and 2.0 ova (range $=1-3$ ).

Corpora lutea were found in the ovaries of 5 of the 12 females $(42 \%)$ that were placed opposite to males but unmated. There was a mean of 3.0 corpora lutea per female (range $=1-6$ ). Ova were found in the oviducts of 3 females; the mean number of ova was 2.3 (range $=$ 1-3).

Corpora lutea were found in two of the five individually housed females $(40 \%)$, with a mean of 3.5 corpora lutea per female (range $=34$ ). The female with 3 corpora lutea also was found to have two ova.

\section{DISCUSSION}

That both mated females ovulated is consistent with the findings of Langford and Clulow (1979). It is notable, however, that 7 of 17 unmated females (both paired and single) also ovulated. It is surprising first, that as many as $40 \%$ of the unpaired females ovulated and, second, that there was no appreciable difference in the percentage of females ovulating as a function of pairing across a barrier from a male versus housing in a single cage.

The Microtus and Clethrionomys genera are two prominent genera of microtine rodents, both of which appear to be induced ovulators (Breed, 1967; Clarke, Clulow, \& Grieg, 1970; Langford \& Clulow, 1979). Within both genera, females may ovulate not only after copulation, but also in response to proximal stimuli from males. However, there appear to be differences between the genera with respect to their sensitivity to more distant stimuli. Within the genus Microtus, females of several species have been found to ovulate when placed across barriers from males. Gray, Davis, Zerylnick, and Dewsbury (1974) found corpora lutea in the ovaries of 2 of 12 paired, unmated female M. montanus. Kirkpatrick and Valentine (1970) found corpora lutea in 1 of 12 female $M$. pinetorum placed across from males. The occurrence of ovulation in $M$. agretis varies with social environment (Milligan, 1974, 1975). However, we have found no evidence in the literature that Microtus ovulate unless placed in close proximity to a male or to his soiled bedding.

Although the present data appear to be the first to indicate that unpaired $C$. gapperi sometimes ovulate, the occurrence of ovulation in unpaired, unmated female $C$. glareolus has been reported by both Andersson and Gustafsson (1982) and Clarke and Clulow (1973), although not by Jemiolo, Marchlewska-Koj, and Buchalczyk (1980) or Westlin and Nyholm (1982). Although the available data are incomplete, they suggest a difference between the genera, with Microtus not ovulating unless placed in relatively close contact with stimuli from males and Clethrionomys ovulating more readily in response to more remote stimuli under at least some conditions.

Whereas corpora lutea were found in $40 \%$ of the unpaired females in the present study, none were found in the isolated females studied by Langford and Clulow (1979). All females in the present study were killed after 2 consecutive days of vaginal estrus. The estrous state of the females in the Langford and Clulow study was not reported. Under our conditions, females came into estrus irregularly, often with relatively long latencies. If that was also true of Langford and Clulow's females, it is possible that few came into estrus and that corpora lutea were not present for that reason.

With a limited number of animals available while our colony was in existence, it was not possible to determine the exact nature of the effective stimuli for ovulation in $C$. gapperi. It is unlikely that the procedure of taking vaginal smears induced ovulation (see Clarke \& Hellwing, 1977, and Langford \& Clulow, 1979). It seems more likely that airborne chemicals from males housed in the colony room reached the females. It would be interesting to study female $C$. gapperi in more complete isolation from males than was possible in this study and to determine whether or not the apparent differences between Microtus and Clethrionomys are real and whether females might occasionally ovulate in complete isolation from males.

More generally, some further elaboration of the categories of "induced" and "spontaneous" ovulation appears called for. Ovulation can be stimulus dependent on at least some occasions in both spontaneous and induced ovulators. Stimuli other than vaginal stimulation are effective in triggering ovulation in some species of induced ovulators. It may be desirable to classify species with respect to the kinds of stimuli that can effect ovulation and not just as "induced ovulators." More refined study of the broad range of stimuli that can trigger ovulation and thus modulate reproductive function is required.

\section{REFERENCES}

Andersson, C. B., \& Gustafsson, T. O. (1982). Effect of limited and complete mating on ovaries and adrenals in bank voles, Clethrionomys glareolus. Journal of Reproduction and Fertility, 64, 431-435.

Aron, C., Roos, J., \& Asch, G. (1968). New facts concerning the afferent stimuli that trigger ovulation by coitus in the rat. Neuroendocrinology, 3, 47-54.

BREED, W. G. (1967). Ovulation in the genus Microtus. Nature, 214, 826.

Clark, J. H., \& Zarrow, M. X. (1971). Influence of copulation on time of ovulation in women. American Journal of Obstetrics and Gynecology, 109, 1083-1085.

Clarke, J. R., \& Clulow, F. V. (1973). The effect of successive 
matings upon bank vole (Clethrionomys glareolus) and vole (Microtus agrestis) ovaries. In J. H. Peters (Ed.), The development and maturation of the ovary and its functions (pp. 160-170). Amsterdam: Excerpta Medica.

Clarke, J. R., Clulow, F. V., \& Grieg, F. (1970). Ovulation in the bank vole, Clethrionomys glareolus. Journal of Reproduction and Fertility, 23, 531.

Clarke, J. R., \& Hellwing, S. (1977). Remote control by males of ovulation in bank voles (Clethrionomys glareous). Journal of Reproduction and Fertility, 50, 155-158.

Conaway, C. H. (1971). Ecological adaptation and mammalian reproduction. Biology of Reproduction, 4, 239-247.

Dewsbury, D. A. (1972). The use of muroid rodents in the psychology laboratory. Behavior Research Methods \& Instrumentation, 6, 301-308.

Dewsbury, D. A., Baumgardner, D. J., SAwrey, D. K., \& Webster, D. G. (1982). The adaptive profile: Comparative psychology of red-backed voles (Clethrionomys gapperi). Journal of Comparative and Physiological Psychology, 96, 649-660.

Gray, G. D., Davis, H. N., Zerylnick, M., \& Dewsbury, D. A. (1974). Oestrus and induced ovulation in montane voles. Journal of Reproduction and Fertility, 38, 193-196.

Jemiolo, B., Marchlewska-KoJ, A., \& Buchalczyk, A. (1980). Acceleration of ovarian follicle maturation of female caused by male in Microtus agrestis and Clethrionomys glareolus. Folia Biologica (Krakow), 28, 269-272.

KirkPatrick, R. L., \& Valentine, G. L. (1970). Reproduction in captive pine voles, Microtus pinetorum. Journal of Mammalogy, 51, 779-785.

Langford, P. E., \& Clulow, F. V. (1979). Reproduction of the female red-backed vole, Clethrionomys gapperi (Vigors), in the laboratory. Canadian Journal of Zoology, 57, 2460-2462.

Milligan, S. R. (1974). Social environment and ovulation in the vole, Microtus agrestis. Journal of Reproduction and Fertility, 41, 35-47.

Milligan, S. R. (1975). Further observations on the influence of the social environment on ovulation in the vole, Microtus agrestis. Journal of Reproduction and Fertility, 44, 543-544.

Westuin, L. M., Nyносм, E. (1982). Sterile matings initiate the breeding season in the bank vole, Clethrionomys gapperi. A field and laboratory study. Canadian Journal of Zoology, 60, 387-391.

Zarrow, M. X., \& Clark, J. H. (1968). Ovulation following vaginal stimulation in a spontaneous ovulator and its implications. Journal of Endocrinology, 40, 343-352.

(Manuscript received for publication March 22, 1984.) 